JSCM T

Journal of Sustainable Construction

Materials and Technologies

J. Sustain. Construct. Mater. Technol. 3(1) (2018) 174-190
Journal of Sustainable

Construction Materials and Technologies

http://www.eds.yildiz.edu.tr/jscmt

\title{
Cibali District; Investigation of External Facing Material Selection In Architectural Structures
}

\author{
A. Bilge Iş1k ${ }^{1, a}$, Yusuf Akyazıc1 $1, \mathrm{~b}, *$ \\ ${ }^{1}$ Faculty of Engineering, Istanbul Aydin University, Florya Campus, Istanbul, Turkey \\ aisik.bilge@gmail.com, ${ }^{b}$ akyaziciyusuf@gmail.com
}

Received May 6, 2017; accepted July24, 2017

\begin{abstract}
In this study, product selection and environmental effects were researched in the facade coatings forming the shells. The exterior wall coverings used in the buildings form the shell of the design. This makes the relationship between the shell of the builder and the outside of the builder. Preferable material properties, resistance to environmental factors, external damage to the environment during the production process and user preferences are important. It is a study to investigate the environmental compatibility and the results of material preferences to be used in accordance with these properties.

In accordance with this purpose; Turkey It is a comparison of preferred exterior facade covering materials by examining the outer shells of the existing constructions built in the Istanbul city Cibali district. Wood, stone, metal, glass, plastic and etc. to examine the selection and application methods made by examining the bearing systems of the coatings.
\end{abstract}

Keywords: Material, Building structure, Historical Process

\section{Instroduction}

The change of the urban identities in the historical process and the formation of identity today are formed by shell design and material preferences in architectural works. In architectural construction, the exterior view is the building element where the primary communication and interaction with the user takes place. In this study, it was chosen as the district of Cibali neighborhood in the historical peninsula region of İstanbul province. The Cibali neighborhood has undergone changes in terms of crust identity in the historical process, and the architectural structures that make up the neighborhood include diversity as a supporting system and exterior appearance. Today, it is aimed to

\footnotetext{
* Corresponding author.

E-mail address: akyaziciyusuf@gmail.com (F. Akyazıcı)

https://doi.org/10.29187/jscmt.2018.21
} 
determine the structural system, exterior view and user preferences of the architectural structures located in the Cibali neighborhood by analyzing them within the neighborhood.

Cibali neighborhood was chosen as the study area. Neighborhood; In Fatih district, Yavuz Sultanselim is located on the west shore of the Golden horn at the center of the Zeyrek and Yavuzsinan districts and is in a mutual position with Kasimpaşa district. The Cibali, an important settlement of the Byzantine period, has been one of the preferred areas of accommodation during the Ottoman period. The name of the region was named as "Porta Puteae" or "Porta del Pozzo" during the conquest of Istanbul by the Ottoman Emperor of Fatih Sultan Mehmet on May 29, 1453 and the name of Cibali with the entrance of Bursa commander Cebe Ali Bey to istanbul. Historically, it is a cultural heritage region where the region has been home to many religions and nations, which have hosted the Spanish Jews, Byzantium Rum and Ottoman Turks. An area where different facade materials have been applied as the research area has been observed with the cultural richness of the Cibali region where different period structures exist. The survey is on 756 buildings within the scope of Cibali neighborhood.

In the scope of Cibali neighborhood, 756 pieces of structural systems and the outer shells integrated into these systems were examined and presented as photographs, and the materials used in the island were classified in color and processed in the map. The structural system and the exterior of 756 structures inside the 47 islands in the Cibali neighborhood were investigated. Within the scope of this review; 185 pieces of wood, 10 pieces of natural stone, 2 pieces of stone coating, 165 pieces of cement plaster, 260 pieces of cement plaster + paint, 4 pieces of composite panel, 11 pieces of bricks, 117 pieces of glass mosaic and 1 piece Façade coating applications on the facade are seen. The classification of 47 islands based on the exterior view of Cibali neighborhood has been converted into a map within the neighborhood. This work presents us with the diversity and diversity of the map view that appeared in the frontal view of the neighborhood.

\section{Effecting Factors Of The Facade Design}

Building materials are tools that give life to the application phase of architectural design. Make exterior and exterior materials in the sense of user and environmental sense; Are the determinants of the occurrence. The traces that material selections leave on people can also be identified by the designer's signature. Designers such as Alvar Aalto, Tadao Ando, and Louis Kahn left their mark on architecture with their choice of materials, and the monument swarmed with materials.

Factors affecting the preferred materials in façade designs; Atmospheric factors can be studied under four main headings as mechanical effects, material properties and user requirements. The facades are directly related to the atmosphere; Solar radiation, atmospheric effects such as water, heat and wind, and reaction to these effects. In this context, the reaction of external facade materials to environmental factors is examined.

Physical, chemical, cost, sustainability and etc. qualities form the properties of the materials

\subsection{Atmospheric Factors}

Since the facades are the outer shell of the design, they are directly related to the atmosphere. The end result of this relationship is exterior facades; Water, temperature, wind, solar radiation, etc. Interact with the effects. Materials to be used on the external surface; The responses to environmental factors should be calculated in advance considering the geographical location of the building and the energy losses in the building use should be reduced. Therefore, exterior design and material selection are important considering these factors in architectural design.

\subsection{Material Properties}

The physical properties to be examined in the material selection of the design are the global data obtained by the test method. This is; External dimensions, unit-volume mass, occupancy, void, water absorption, water permeability, expansion etc. And features. Size; The width, height and height of the materials to be used. Deviations in this 
measure will disturb the feeling of being given in the outer shell. The weight of the material in the absence of space forms its own mass. The ratio of the natural size of material to the mass is called unit-volume mass. The difference in the mass value of any material between unit-volume mass represents the air pores in it. As this difference is turned on, the space inside becomes larger. Volumetric expansion of the materials used on exterior surfaces is important in material preference. The volumetric properties are measured by the reaction of the temperature changes in the environment. Growing mass by decreasing intensity in heat increase and trying to return to the former form in heat reduction enables the deterioration of material in this physical process to interact with other environmental influences (water, moisture, etc.) in the next process and to damage the shell.

The results of the reactions of the bodies affected by mechanical loads constitute the mechanical properties of the material. The mechanical properties of the material are even more important when considering the possibility that the wall is a crust, except that the exterior wall materials to be used are the covering material. In design, it is necessary not to undergo physical changes by calculating the mechanical loads that are under the influence of a shell composed of masonry stone walls. The height of the wall and a stone that is compatible with the mechanical loads which will be increased further makes the choice of long life and usable. Since the testing of preferred materials can be done in a laboratory environment, using a globally accepted data for a designer, ensuring post-implementation sustainability of the design, and taking measures against the risk of human life under the influence of natural disasters such as earthquakes

\subsection{Sustainability-Eco Design}

The ecological design principles are to design our built environment and our lifestyles to integrate in a harmonious and flawless manner with the natural environment in which the biosphere (Figure 1) is located. The main aim in eco design is; the air we breathe the water we drink and the living conditions, as well as the pollution of the soil we produce our priority foods and clean hiding. Human beings can continue their lives; to the quality of the natural environment (Figure 2) and to the ability of humankind to sustain without harming, undermining and polluting the natural environment. Human health depends entirely on the protection of nature.

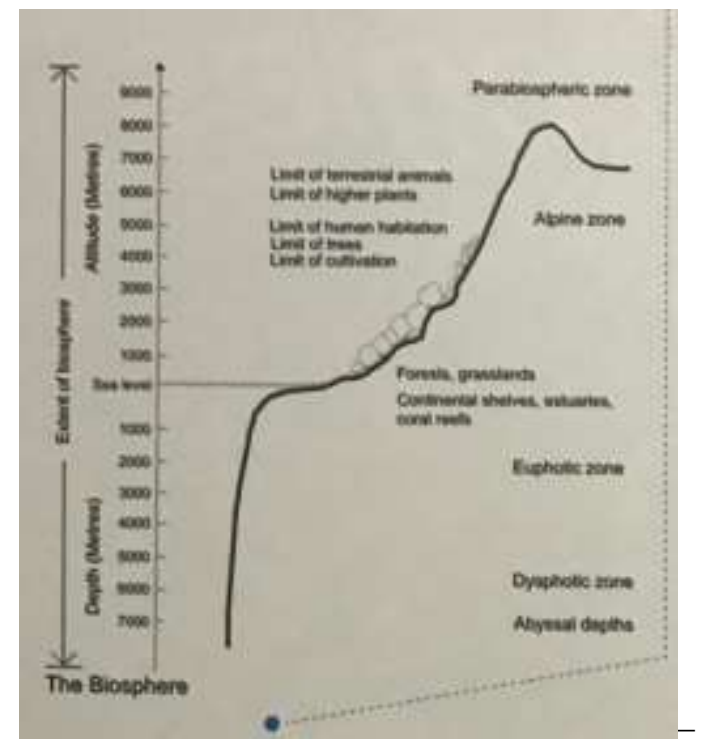

Fig. 1. Figure Natural Circumference Adaptation. 


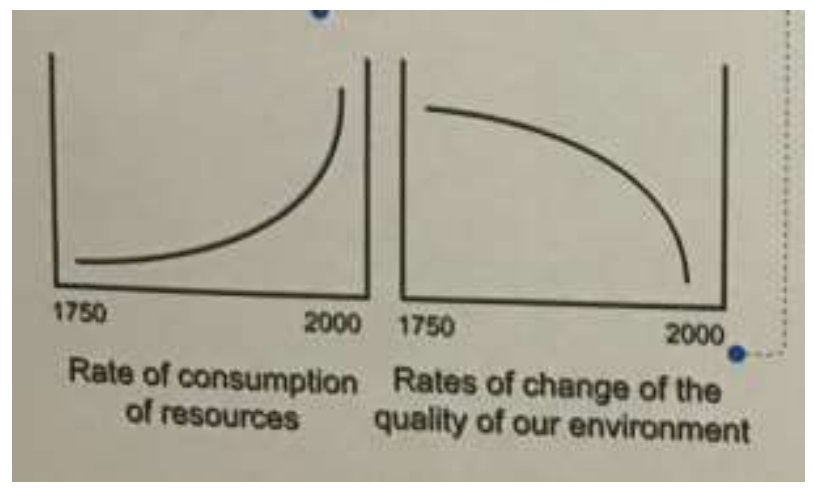

Fig. 2. Impact of the Consumption of Resources on the Quality of the Environment.

Mankind is the living species that pollutes nature the most. The communities of people who lived in nature long ago, are now a problem with their haphazard settlements and the garbage they leave around. People who occupy less than $1 \%$ of the earth make up $99 \%$ of the environmental pollution.

With natural environmental pollution, the consumption of non-renewable energy increases day by day. Industrial industries end without fossil fuels. Without electricity, electronic devices and many systems will not work, and if the oil and electricity, which are the most important of the modern civilization, is not human, the Stone Age will return.

It is necessary to base the system on a rooted environment that describes the common life relation between the built environment and the natural environment. Everything in human life, semi-finished products and what comes to mind, should be considered and applied in the ecological system. The provision of necessity has not yet been fully resolved among environmental designers.

Eco design is not a design made by using products such as solar collector, wind generator, photovoltaic and bio stimulator with the products produced by today's technology. The use of these devices is not wrong, but they do not express eco design alone. The use of these products is derived from the design concept created by the designers who think it is the ingenuity, and architecture supports this understanding in the magazines. However, this is only eco device architecture. It is the reflection of the technology that removes us from nature.

Green design equality does not mean low energy cost. The goal in green design is to integrate with the environment through design. Otherwise, a structure we have equipped with technological devices does not mean energy saving. While the important point in engineering design is the result, the aim in environmental design is environmental and environmental harmony. In systems designed, harmonious integration should be our priority. When we have completed the process of life in the built environment, we must think back in the natural system.

Although this paper is easy to see, it is a difficult and complex task to achieve in its entirety

\section{Facade Design}

First of all, do the effects of the structures on the human beings are realized through the communication between the external façade or appearance and the human eye. This relationship creates the influence of the exterior design on the human being. Many designers, on the other hand, see this as the introduction and primary sensation of building exterior design. The visual effect of the materials used in exterior design is important. The preferred material can reduce the emphasis of the structure as much as possible.

Design; The interior designed with the user's requirements in mind, can work as a whole with the shell. The textures and images created on the external fronts, where people's visual communication is primarily performed, are 
important so that the interior that is desired to be given inside can also be felt by the surrounding voyage. In the Berlin Jewish Museum, designed by architect Daniel Libenskind in Berlin in 1989, the feelings and feelings to be given in the interior have been successfully processed in the shell. The concrete exterior material of the design was preferred to create a feeling of coldness in Jewish genocide. The splintered David star images used on the exterior; in the genocide, the people in the environment feel the disintegration and loss of Jews (Figure 3).

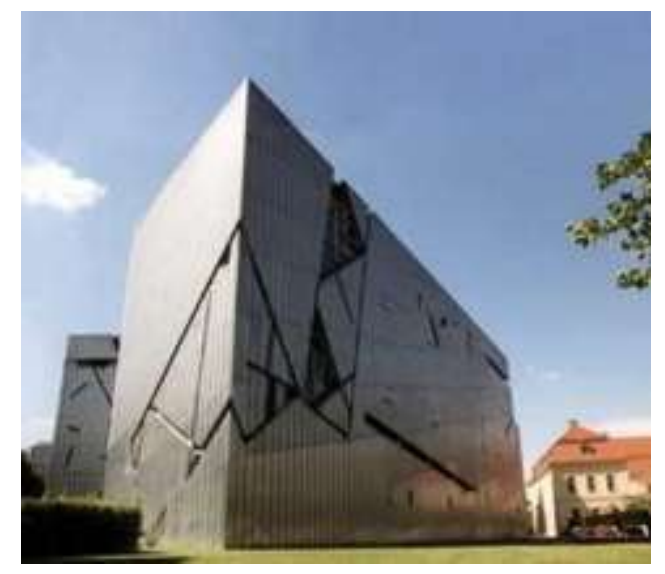

Fig. 3: Berlin Jewish Museum, Libenskind, D. 1989

\subsection{Figure Walls - Exterior Walls}

The two main classes are divided into interior walls according to the functions of the walls and exterior walls which we can call as the outer shells. The outer walls we call shell; The relationship between the work and the environment. In the cases where the outer walls on the buildings are not the finishing elements, the exterior facade covers the crust. In these cases, a holistic relationship is needed between the exterior facades and the wall.

Today, as a choice of exterior wall material, Stone, brick, mud brick, briquette, aerated concrete, wood, glass, plastic and so on. Materials are preferred. These materials can be used on the outer walls as a carrier-dividing or dividing wall according to the material properties. Common characteristics expected from materials are; Sound insulation, heat insulation, protection against weather effects, integrity or aesthetics with exterior facades, fire resistance. The walls are perceived as an integral part of their insulation and protection requirements, since they act jointly with exterior facade coatings. The choice of materials in the exterior walls and coatings must be calculated and integrated with the design during the projecting phase.

\subsection{Facade plaster}

Cement, lime, gypsum, etc. applied on exterior walls of ladies. (1) which are formed by using fine sand, aggregate and water, and by means of hand tools such as machine or trowel.

Plaster applied on the exterior walls; Rough plaster, primer and fine plaster. Although it is possible to see coarse and fine plaster layers frequently in the plaster samples applied in our country, the primer layer is not preferred (Figure 4-5).

The first layer applied on the outer wall is called rough plaster. The requirement of the primer layer applied on the coarse plaster and used to reduce superficial disturbances is related to the suitability of the surface to the fine liquid after coarse plaster application. If the surface is suitable for application of thin plaster after application of plaster, thin plaster application is performed without applying primer layer. 


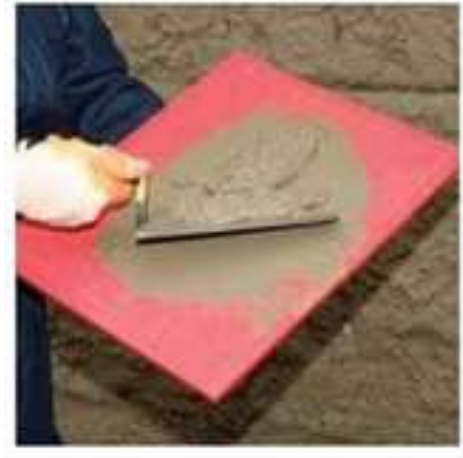

Fig. 4. Wall plastering using trowel

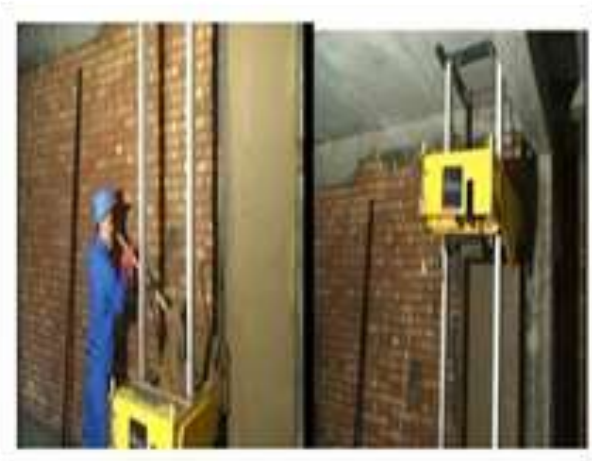

Fig. 5. Wall Plating with Machine Aid

According to the mortar materials used, types of rough plaster; Lime coarse plaster mortar, reinforced coarse plaster mortar, cemented coarse plaster mortar and perlite coarse plaster mortar (28).

Limestone plaster mortar: Lime is a mortar obtained by mixing sand and water. During the periods when cement was not widely available, it was the most preferred mortar in the market conditions. Although the setting time is longer than that of the cement, the sound and heat permeability is higher than the cement mortar.

Cementations plaster mortar: plaster mortar containing sand, cement and water. The set-up time is a short mixture and needs to be applied quickly.

Lime reinforced cementations plaster mortar: plaster mortar obtained by adding lime to cement mortar plaster. The problem of shortness of the cement plaster-mounted set period can be improved by adding lime.

Perlite rough plaster mortar: plaster mortar containing cement, water and perlite. It is different from other mortars that perlite is found instead of sand in its element. The perlite contained therein is a lighter material, which reduces the amount of charge in the structure and is a less permeable mortar for heat and sound insulation than other mortars.

Thin plaster the last layer of plaster application; applied layer to create a smoother and cleaner surface. The mixture is prepared according to the applied plaster mixture and contains differences like fine sand. The mixture amount suitable for thin plaster mortar prepared with lime is $1 \mathrm{~m} 3$ thin plaster sand, $1 / 3$ lime paste and 110 lt water (Figure 6-7).

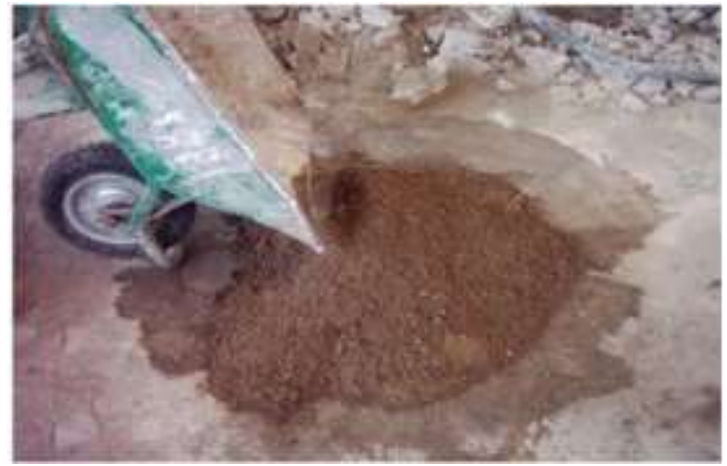

Fig. 6. Preparation of sand for fine plaster mortar

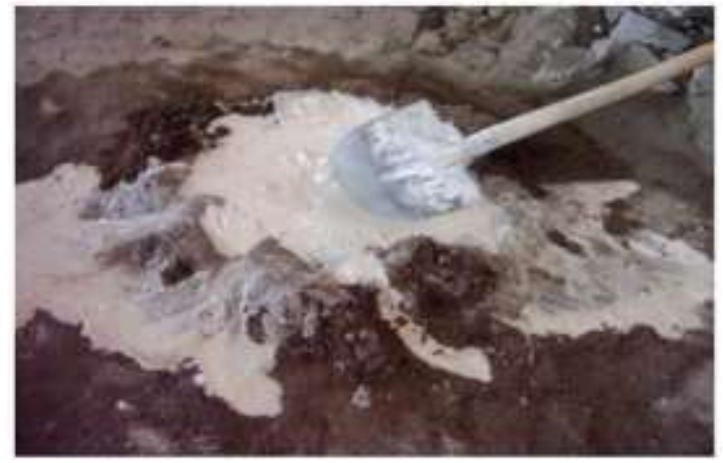

Fig. 7. Mixing of sand and lime 
The average amount of mixture which is suitable for thin plaster to be prepared with cement is $1 \mathrm{~m} 3$ fine plaster sand, $400 \mathrm{~kg}$ cement and $150 \mathrm{lt}$ water.

1 cubic meter of fine plaster sand, $250 \mathrm{~kg}$ of cement, 0.1 cubic meter of lime scale and 135 liters of water, suitable for thin plaster to be prepared with lime reinforced cement.

\subsection{Stone Façade}

Natural stones, which are the strongest facade materials against natural factors, are applied to the outer wall of the building, Methods. When the weight of the stone reaches to the foreground, it can be seen by bonding materials such as volcanic tuff, travertine and sand stones, marble, granite and so on. Methods such as screwing and clamping are recommended in materials where the weight added to the structure is higher (Figure 8).
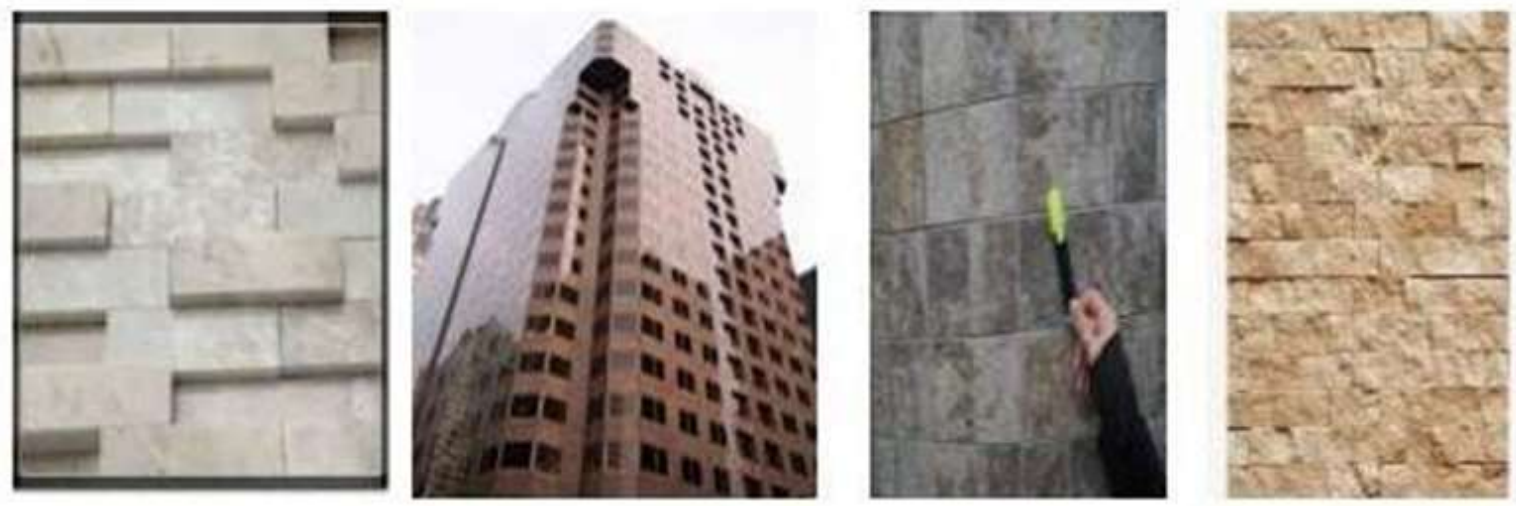

\section{Fig. 8. Marble Granite Limestone Travertine}

\subsection{Glass and Steel Facades}

Architectural constructions have undergone structural and structural changes throughout history according to the requirements of human beings. In some cases, architectural changes have changed and improved the way people live. Economic and technological changes in the world history show the primary effect of changes in building materials.

Until the 17th century, glass used in architectural constructions remained a building material that could be used in small openings because it could not be processed in large parts due to production conditions. It has become indispensable for human beings because of its ability to reduce the effects of environmental factors and to make light work. The industrial revolution is the primary effect of initiating glass and steel relations on issues such as the growth of glass sections, mass production, steel production, and production costs.

Examples of use of glassware are known as the beads of the B.C. 25th century. However, the glass has entered into many stages of human life. The first use of glassware in constructions is seen as glass mosaic in Roman age constructions. The use of Cam as the facade material in the buildings began with the applications of the Medieval Gothic Architecture. It is used as a glass structure with light- colored irregularities in the gothic churches with high resistance and transparency despite the heat changes. In the 16th century, in order to make use of daylight in building interiors, housing and commercial buildings were started to be used later. In the 18th century, the first $2,135 \mathrm{~mm} \times 1,350 \mathrm{~mm}$ glass plates were produced. The glass material used for closing the building gaps has increased the effect on the exterior design. In the 19th century, all of the facades were covered with glass, and as a result, the necessities such as heating-cooling, lighting and ventilation came to the forefront.

Steel, which is indispensable building material today, has entered the life of human beings, which according to a theory, is the result of the fire that occurs in the mountains of Goose in antiquity and the position of iron can form in 
the soil. Iron and steel are not used in constructions until the 18th century with the existence of human beings close to 5000 years. The first use of steel materials in construction was the Coalbrookdale Bridge, built on the Severn River in England in 1778.

Pompidou Center: The Pompidou Center, a project deserving of the first prize of Renzo Piano and Riscard Rogers; Opened in 1977, it is an architectural structure that combines the museum concept with the cultural center concept (Figure 16). The harmonious use of glass and steel materials in the building has made the service areas a solution centered on different approaches on the facades. In the building which functions as a cultural center; It consists of the public library with 371,000 books, the Industrial Design Center, the National Museum of Modern Art, the Continuous Exhibits Area and the Music Research and Coordination departments (Figure 9)

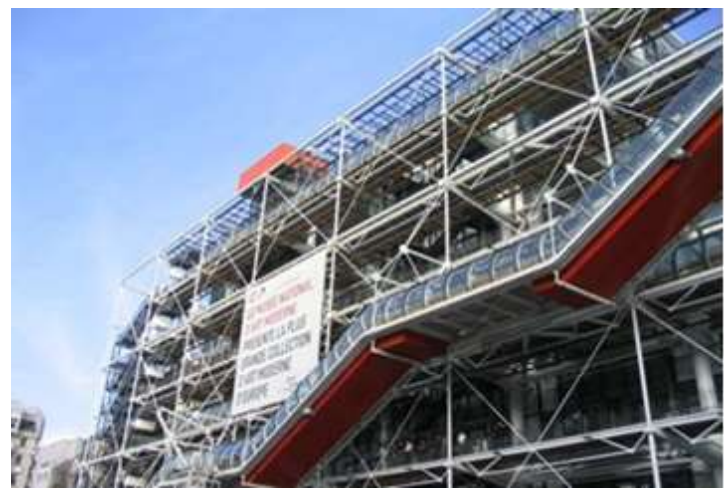

Fig. 9 - Pompidou Center

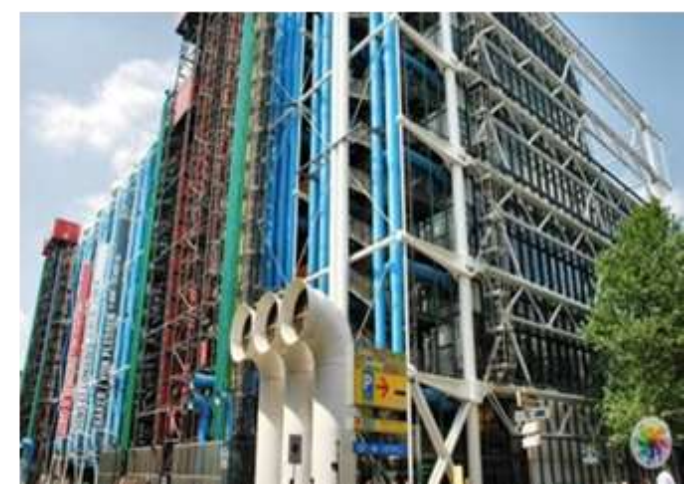

Fig. 10 - Pompidou Center

Louvre Pyramid: Paris' famous Louvre museum has a new meaning and dimension due to the influence of glass and steel and the Louvre pyramid designed by Pei. The Louvre pyramid, which has become one of the symbolic structures of France, sits on a $38 \times 38$ meter area and has a modern approach to the surrounding cultural and architectural fabric with its transparent structure (Figure 11-12).Under the pyramid library, bazaar, rest, 400 person conference hall, etc.

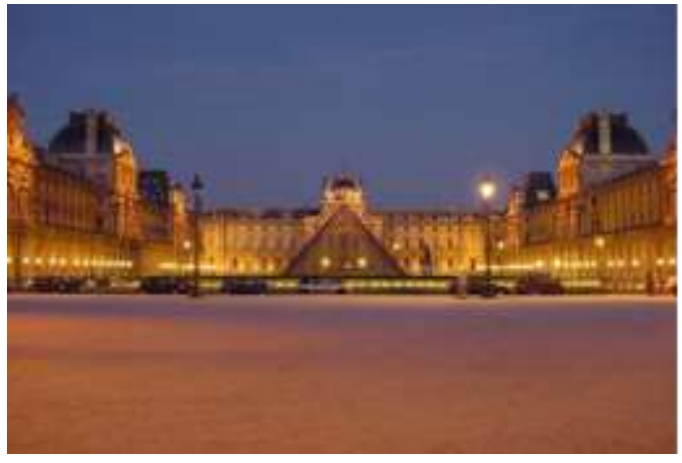

Fig. 11. Louvre Museum

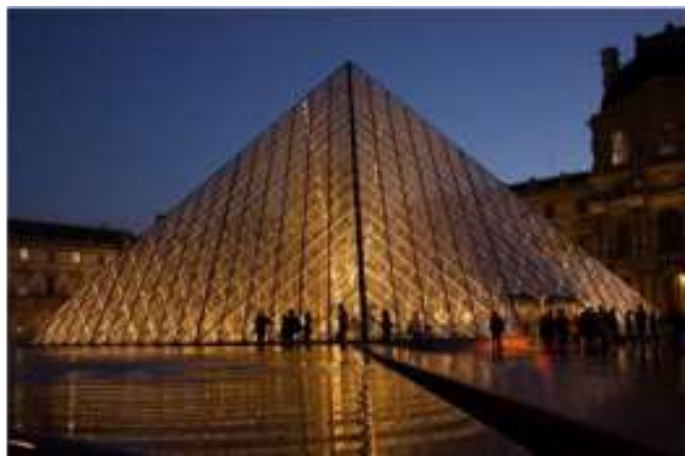

Fig. 12. Louvre Pyramid 


\subsection{Concrete - Reinforced concrete block}

Concrete; Cement, sand and aggregates, it is a mixture containing solid materials. It has the most common use among building materials. The form of the desired form is prepared and the mold is poured in liquid form. Used inside; Cement and aggregate ratio determine the surface hardness and strength of the concrete.

The use of cement, which is a mixture of concrete, in constructions was first observed in BC. It is seen on a wall in Thebes, built in Egypt in 1950. The first use of concrete as a mixture; It is possible to see it on the dome of the Pantheon which was built in $\mathrm{AD} 125$ (Figure 21). It is possible to see the use of concrete in historical buildings predominantly during the Roman period. By using it in liquid form, many forms can be easily applied (Figure 13).

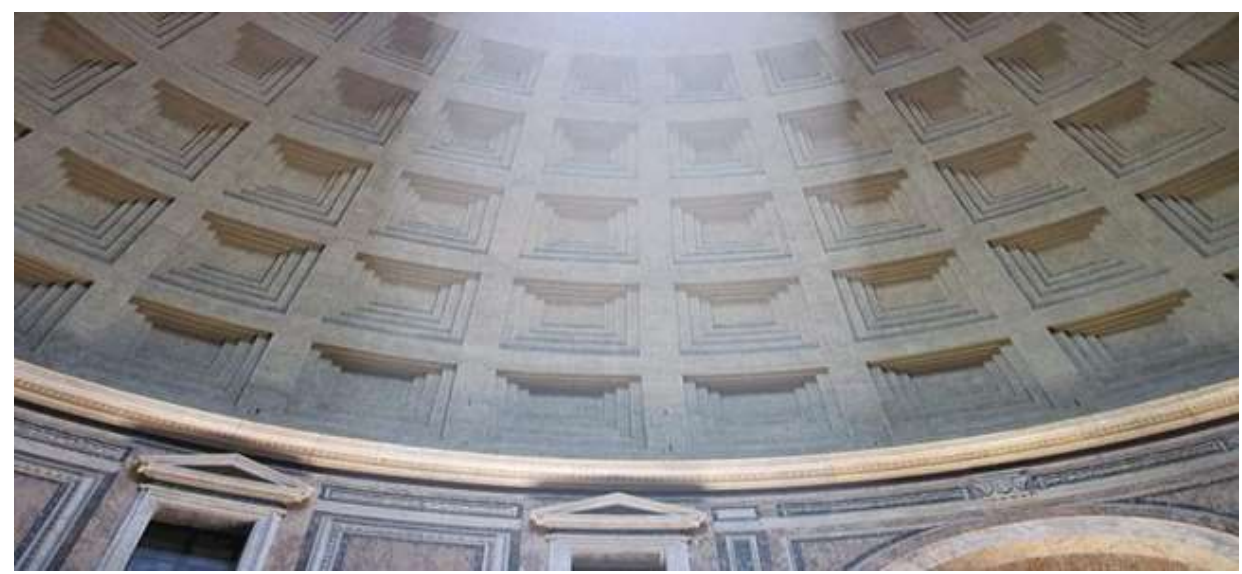

Fig. 13. Pantheon, Rome MS 125

Cement, which is regarded as the binder of concrete; Written sources by Marcus Vitruvius first BC. De Architecture is estimated to be written in the 27th century. In this work, a mixture of pumice (volcanic ash) and lime which serves as a cement is explained by the Romans. 2 pieces of pozzolan and 1 part of the mixture of materials with lime proportions are obtained with the resulting adhesive material works even after 1500 years. A.D. Roman Cement was used in the arch bases of Hagia Sophia, built by Roman King Nero between 532 -537 (Figure 14).

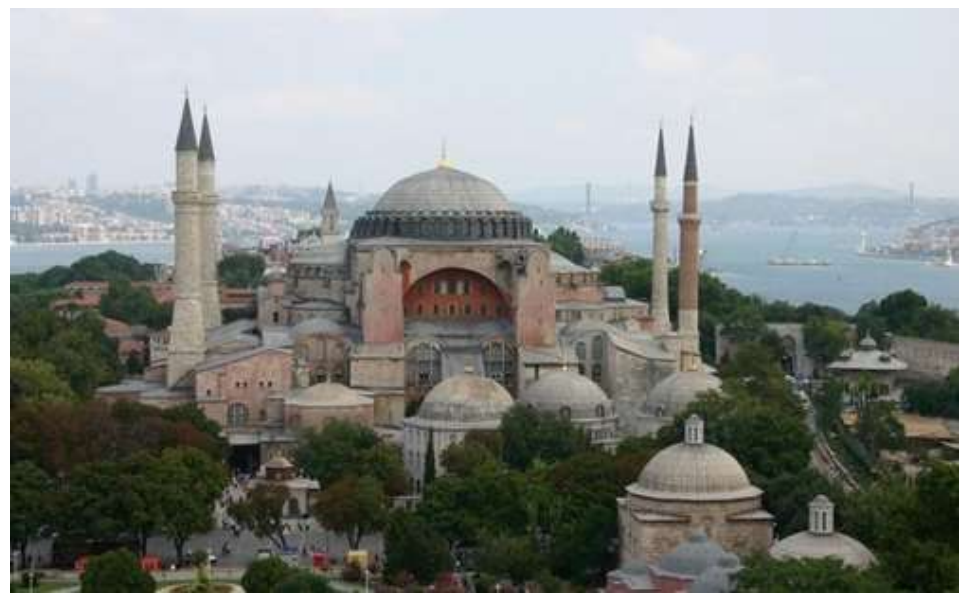

Fig. 14. Hagia Sophia Museum, M.S. 532-537 
When steel and iron are used, strength and carrier properties are strengthened. When used in standard measurements, it is now possible to perform faster applications using prebuilt blocks.

Reinforced concrete constructions started as a result of industrial revolution and new quests after the 18th century. It has been found to solve the problems of using steel and to solve the problems of usage of two different materials in concrete-steel relation. The inadequate strength of the concrete has been increased with the steel frame inside. These properties made the use of concrete steel the world's most popular choice after the industrial revolution.

The first reinforced concrete structure in Turkey is located on Istanbul Taksim street. Antuan Catholic church is known. It was designed and built in 1906 by Italian Giulio Mongeri in Italian Neogothic style. In 1912, a worship service was opened. St. The Antuan Catholic Church is the leading church that exemplifies the use of concrete.

\subsection{Wooden Facing}

Timber construction material; It is a natural building material and thanks to the spontaneous formation of the forest in nature, the material of this material is facilitated and used throughout the history. As a façade cladding, the use of timber has positive and negative effects on the construction. Stone, brick, etc. The effect of the dead load on the structure is less than that of the materials forming the dead weight in the structure. The resistance to water is the main factor that needs to be protected. Factors such as water absorption and swelling due to water cause problems such as shrinkage, fracture or cracking after drying due to the effect of sun.

The other negative aspect of wood is the decay feature. If necessary protective measures are not taken; Wood worms, fungi, bacteria, insects will disrupt the structure of the wood and render it unusable (Picture 15).

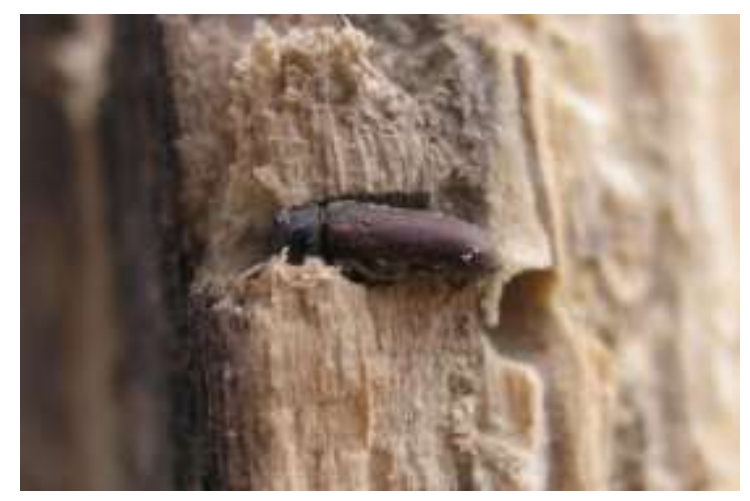

\section{Fig. 15. The tree has settled inside}

Natural wood or treated wood covering materials applied on the facades are applied horizontally or vertically in concrete, brick and wood flood systems. In order to ensure the smoothness of the outer surface of the pre-application structure, the grid system to be used for the installation of the wood veneer material is made of dubels, nails; Surface use is made more convenient by using auxiliary equipment.

Another major negative feature of timber construction materials is resistance to fire. It is a conveyor system element that is allowed to be used up to 3 -storey timber construction beginning at 150 degrees.

\subsection{Composite Panels}

Composite panel is a type of building material used instead of traditional wood or steel. These panels are lighter than solid wood or steel but provide strength and structural strength at the top. There are three basic types of 
composite panels: artificial wood, aluminum and fiberglass. Each of these panels can consist of a lightweight system sandwiched between layers of the same material or layers of some protective material.

The artificial wood composite panel is typically made of sawdust blended with pressed wood fiber or epoxy resin. The wood is milled or made into a thin paste, then dried. The dried fibers are mixed with the epoxy and are layered at high heat and pressure levels. Depending on the type of wood fibers used, this pane is also known as medium density fiberboard or MDF (Figure 16).

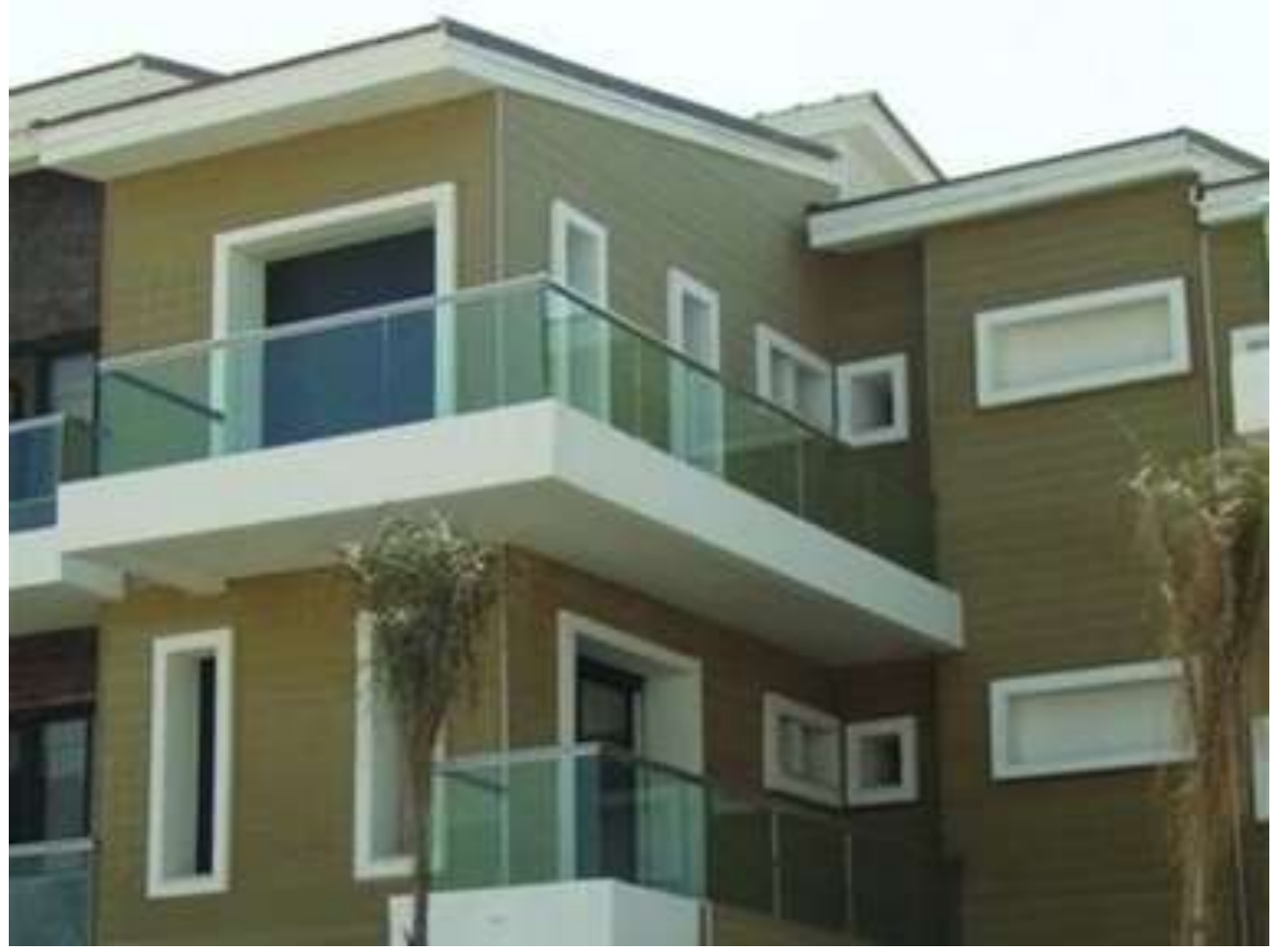

Fig. 16. Application example of Wooden Composite Panel 
Aluminum composite products are called sandwich panels. These consist of a light core wrapped in thin aluminum sheets. The core may be made of hard foam or resin coated cardboard which is shaped like a honeycomb. These panes provide strength at levels similar to conventional steel construction, but the dead load burden generated in the structure is less than in other systems. These panels are used to create light-weight vehicles in the transportation and aviation sectors and powerful places to carry full load (Figure 17).

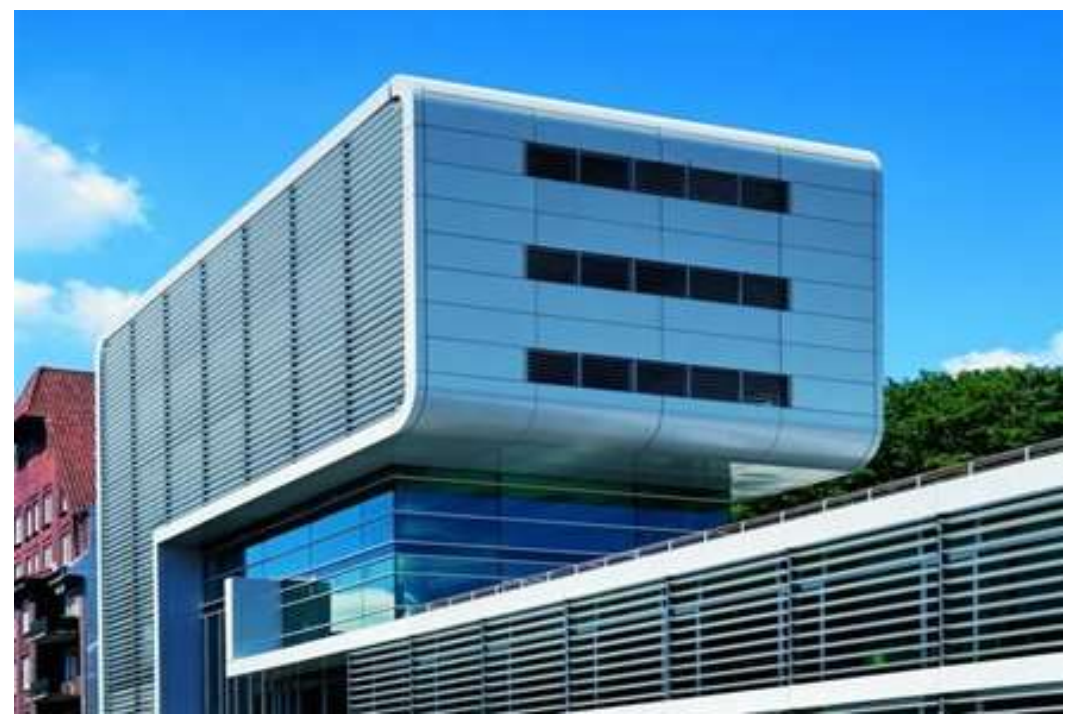

Fig. 17. Application example of Aluminum Composite Panel

A composite panel consists of a combination of fiberglass, foam, and epoxy resin. Typically, these materials are assembled into a foam core surrounded by fiberglass sheets. This type of composite panel is widely used in waterbased applications. Many surf boards and kayaks are made of glass fiber panels, such as boats and other marine vessels. The lightness of the panels helps prevent the tank from swimming, allowing the panel's high power to carry passengers or cargo.

\section{HISTORY OF CİBALİ DISTRICT}

Cibali; Within the provincial borders of Istanbul, Yavuz Sultanselim is located at the center of the districts of Zeyrek and Yavuzsinan on the west coast of the Golden horn and is in a mutual position with Kasımpaşa (Figure 18 - 19).

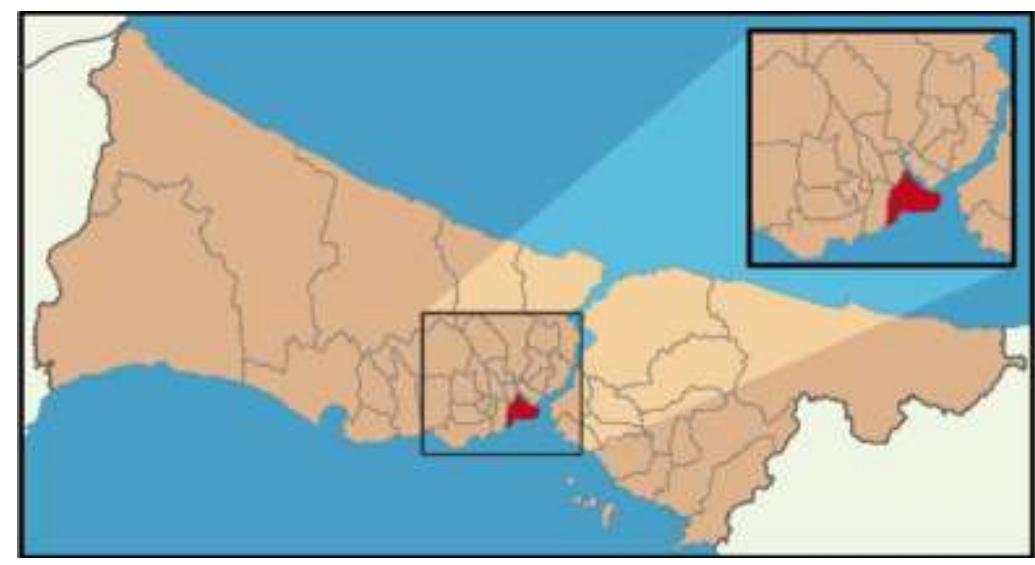

Fig. 18. Fatih District of Istanbul Historical Peninsula 


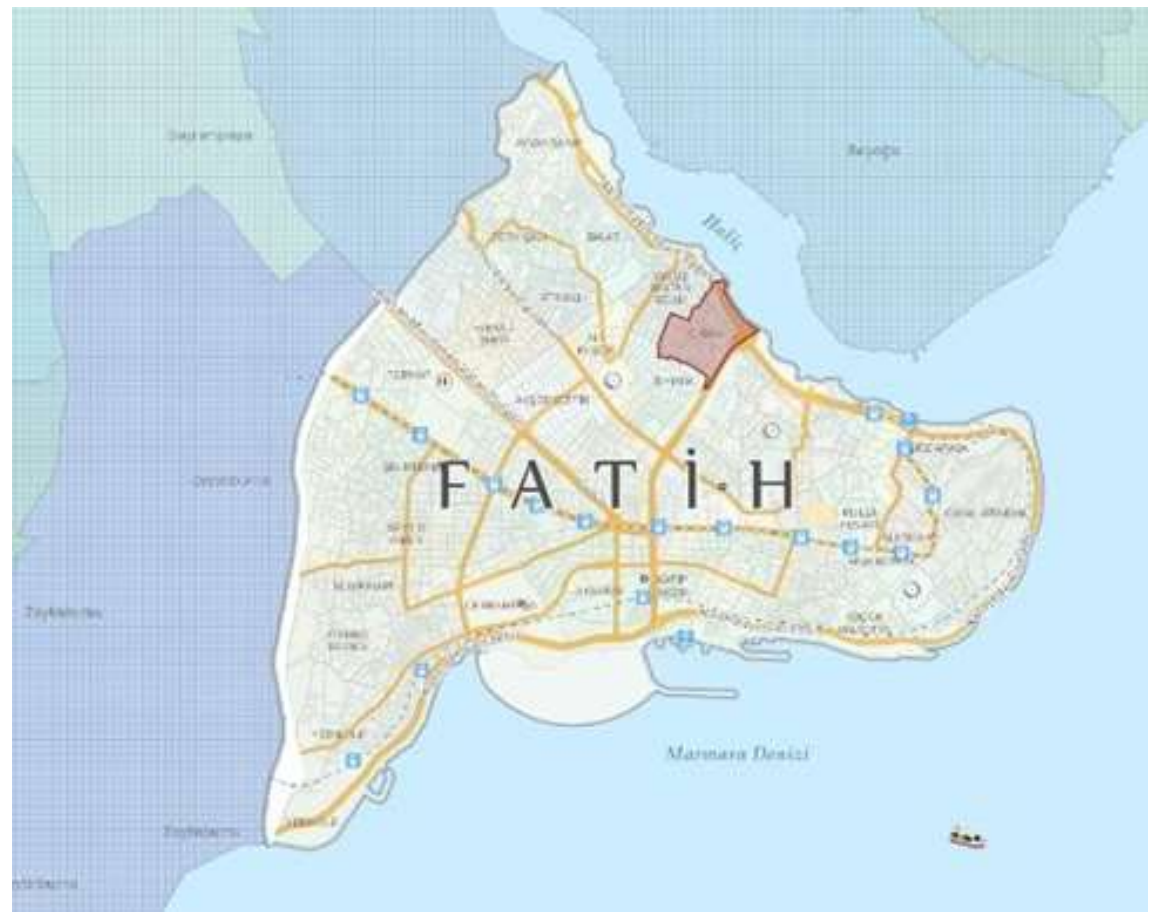

Fig. 19. Historical Peninsula Fatih District Cibali Neighborhood

Today, the Cibali Gate is the only access point to the cibali neighborhood in the city wall, which is known as the door and opens a small lima in the estuary during the Byzantine period. It is known that this door was named "Porta Puteae" or "Porta del Pozzo" by the Spanish Jews residing in Byzantine period in the gate of the mosque.

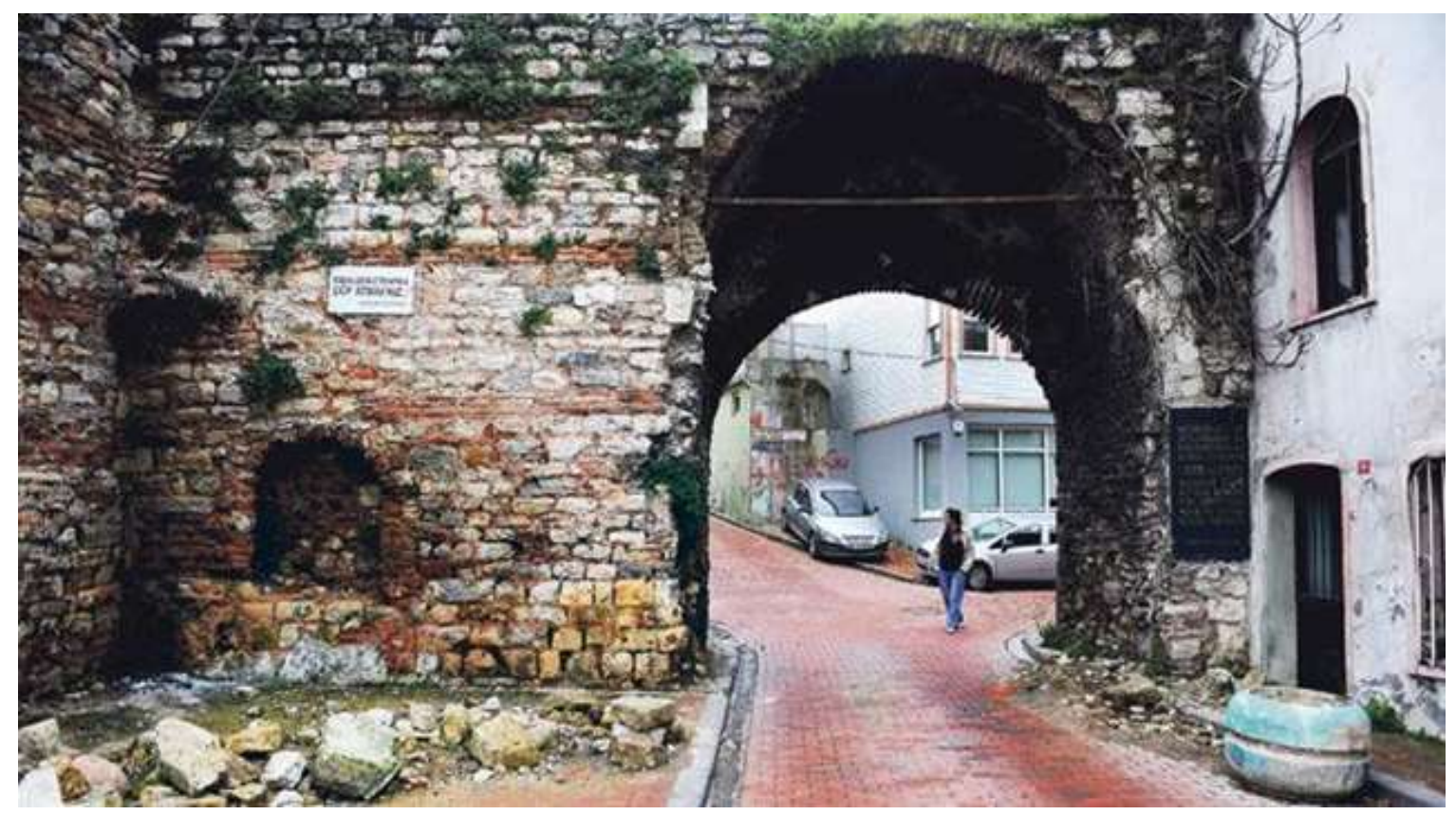

Fig. 20. "Porta Puteae" or "Porta del Pozzo" Nibble Gate 
The Ottoman Emperor Fatih Sultan Mehmet Han entered Istanbul from the door called "Porta Puteae" or "Porta del Pozzo" of Bursa commander Cebe Ali Bey in the conquest of Istanbul on May 29, 1453 and over time this door was called Cibali Gate district Cibali. 18th Century Then it became a district where only the Muslim Turks in the Cibali district where the Rum and the Jews lived. The neighborhood where the mansion was built by the master Piri Reis has become a popular settlement over time.

The neighborhood of Cibali has survived fires in the historical process, which have almost collided with the fires and will be called the whole neighborhood. The end of these fires has been the disappearance of the architectural structures fires many times. These fires are according to Istanbul fire department records:

1714 Pre-Tulumbaids Period:

- 1627 Nibal Fire

- 1688 Nibal Fire

- 1693 Fire of Nibble and Fire of Ayazağakapı

1714-1826 The Janissary Tulumbaids Period:

- 1714 Navy Fire

- 1720 Nibal Fire

- 1750 Nibal Fire

- 1753 Navy Fire

- 1756 Nibbling Fire: 70 baths, 580 mills and ovens, 10 Khans, 200 Mosques and Masjid, 1000 shops, 800 residences were burnt.

- $\quad 1780$ Nibal Fire

1826-1874 Neighborhood Tulumbers Period:

- 1833 Nibali Fire

- 1918 Nibal Fire: 7500 buildings were burned.

- 1957 (20 December) Fire of Cibali: 2 warehouses and 2 workshops were burnt.

- 1959 (July 15) Fire of Cibali: 1 warehouse, 2 workshops and 1 house burned.

- 1959 (27 July) Fire of the Cibali: 1 of the bullets burned.

- 1959 (9 August) Fire of the Cibali

- 1971 (3 May) Fire of Cibali: 3 houses were burnt.

\section{Analaysis}

The structural system and the exterior of 756 structures inside the 47 area in the Cibali district were investigated. Within the scope of this review; 185 pieces of wood, 10 pieces of natural stone, 2 pieces of stone coating, 165 pieces of cement plaster, 260 pieces of cement plaster + paint, 4 pieces of composite panel, 11 pieces of bricks, 117 pieces of glass mosaic and 1 piece Façade coating applications are observed on the facade (Table1). 
Table 1. Historical Peninsula Cibali District 47 Island Façade Analysis

\begin{tabular}{|c|c|c|c|c|c|c|c|c|c|c|}
\hline 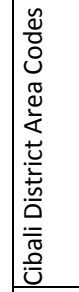 & 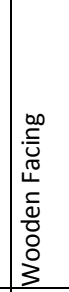 & 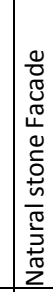 & 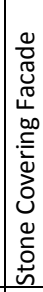 & 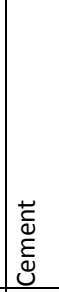 & 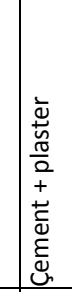 & 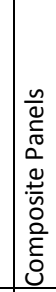 & 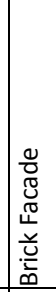 & 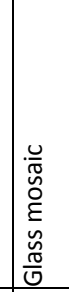 & 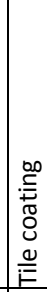 & 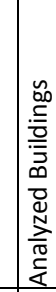 \\
\hline 1000 & 1 & - & 1 & 4 & 2 & - & - & 3 & & 11 \\
\hline 1004 & 2 & - & - & 3 & 3 & - & - & - & 5 & 8 \\
\hline 1005 & 3 & - & $F$ & 7 & 5 & 1 & - & 2 & $F$ & 17 \\
\hline 1006 & - & - & $E$ & - & 4 & -1 & - & 3 & - & 7 \\
\hline 1007 & 14 & 1 & 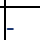 & 13 & 19 & + & - & 3 & 4 & 50 \\
\hline 1008 & 13 & 1 & - & 12 & 18 & - & - & 3 & - & 47 \\
\hline 1010 & 1 & - & $F$ & 2 & 6 & 1 & - & 3 & 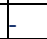 & 12 \\
\hline 1001 & - & - & - & - & 1 & -1 & - & - & - & 1 \\
\hline 1016 & 6 & 1 & 4 & 2 & 16 & - & - & 5 & $E$ & 30 \\
\hline 1017 & 7 & - & - & - & 7 & t & 1 & 2 & 5 & 17 \\
\hline 1018 & 2 & - & - & 1 & 5 & -1 & - & 1 & 7 & 9 \\
\hline 1019 & 6 & 1 & 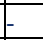 & 2 & 16 & -1 & - & 5 & - & 30 \\
\hline 1020 & - & 1 & - & 2 & 3 & - & - & - & - & 6 \\
\hline 1021 & 14 & - & - & 1 & 8 & 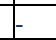 & - & 2 & - & 25 \\
\hline 1022 & 1 & 1 & - & 4 & 4 & - & - & - & 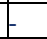 & 10 \\
\hline 1023 & 1 & - & - & - & 6 & F & - & - & t & 7 \\
\hline 1024 & 5 & - & + & 1 & 3 & -1 & - & 1 & - & 10 \\
\hline 1025 & - & - & - & 1 & 4 & - & - & 2 & - & 7 \\
\hline 1026 & - & - & - & - & 1 & - & - & - & - & 1 \\
\hline 1043 & 3 & - & T & 5 & 3 & 2 & - & 1 & - & 14 \\
\hline 1045 & 2 & - & 1 & 1 & 8 & 1 & - & - & 5 & 13 \\
\hline 1046 & 1 & - & $E$ & - & 2 & - & 1 & - & - & 4 \\
\hline 1047 & - & - & - & - & 1 & F & - & - & - & 1 \\
\hline 1050 & - & - & - & - & 1 & F & - & - & 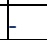 & 1 \\
\hline 2160 & 15 & 1 & - & 7 & 22 & 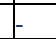 & - & 7 & 7 & 51 \\
\hline 2165 & - & - & - & 7 & 1 & - & - & 7 & 1 & 16 \\
\hline 2168 & 2 & - & $F$ & 1 & 3 & F & - & $F$ & - & 6 \\
\hline 2176 & 6 & - & - & 3 & 1 & - & - & 2 & - & 12 \\
\hline 2177 & 3 & - & 1 & 13 & 6 & -1 & - & - & - & 22 \\
\hline 2178 & 3 & - & F & 1 & 3 & - & - & 1 & - & 8 \\
\hline 2179 & - & - & $F$ & 7 & 2 & -1 & - & 8 & 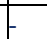 & 17 \\
\hline 2180 & 1 & - & f & 4 & 1 & 1 & 1 & 12 & - & 19 \\
\hline 2181 & 2 & 1 & - & 15 & 4 & F & - & 11 & - & 33 \\
\hline 2183 & 7 & 2 & F & 5 & 7 & - & 2 & 4 & - & 27 \\
\hline 2185 & 2 & - & + & 4 & 4 & + & - & - & - & 10 \\
\hline 2186 & 9 & - & - & 4 & 10 & F & 1 & 4 & & 28 \\
\hline 2188 & 23 & - & - & 16 & 15 & 1 & 2 & - & - & 56 \\
\hline 2189 & 3 & 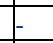 & $E$ & - & 2 & - & - & - & - & 5 \\
\hline 2190 & 3 & - & + & 2 & 1 & + & - & 1 & & 7 \\
\hline 2191 & 1 & 1 & - & 3 & 4 & & - & - & & 9 \\
\hline 2192 & - & $E$ & $E$ & 4 & 9 & 4 & 1 & 6 & - & 19 \\
\hline 2197 & 2 & - & T & 3 & - & 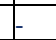 & 1 & 7 & & 13 \\
\hline 2198 & 4 & - & - & 1 & 4 & - & - & 4 & & 13 \\
\hline 2199 & 8 & - & - & 2 & 8 & - & 2 & 5 & & 25 \\
\hline 2200 & 3 & - & - & 1 & - & 1 & - & 1 & - & 5 \\
\hline 2215 & 4 & - & 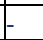 & - & 2 & - & - & - & & 6 \\
\hline 2527 & 3 & - & - & 1 & 5 & 1 & - & 1 & & 11 \\
\hline Total & 185 & 10 & 2 & 165 & 260 & 4 & 11 & 117 & 1 & 756 \\
\hline
\end{tabular}




\section{Conclusion}

In this study, 756 building carrier systems in 57 islands in the historical Cibali district were investigated and exterior facade coverings were researched and classified according to the external appearance preferences within the neighborhood and presented on the map in the context of the neighborhood. Cibali neighborhood has survived very big fires in the historical process, and the buildings which will be destroyed twice in time have disappeared as a result of fires. The renovation works and the historic works that we inherited from the historical process have examined the architectural structures within the district. As a result of these studies and examinations, the following data were obtained.

In 756 buildings examined at Cibali neighborhood; 185 pieces of wood, 10 pieces of natural stone, 2 pieces of stone coating, 165 pieces of cement plaster, 260 pieces of cement plaster + paint, 4 pieces of composite panel, 11 pieces of brick, 117 pieces of glass mosaic and 1 piece of tile coating were found.

As a result of the inspection made on wooden facades, protection measures have not been taken and as a result the facades are damaged, Deformations are seen. Wooden façade constructions are preferred as wood and masonry systems. Wooden façade constructions in the neighborhood were preferred by $24.5 \%$. The natural stone and natural stone facade of the building has been examined in 12 facades, and the masonry stone system, which is the supporting system of these structures, is still continuing in the outer shell. These structures are the Mosque and fountain structures built during the Ottoman period. Within the scope of the neighborhood there are $1.6 \%$ buildings with natural stone and natural stone facade facades.

They are applied on roughing plaster or rough plaster + fine plaster which is used mainly in masonry structures. These practices are observed in $56.2 \%$ of the examinations within the neighborhood. In these structures, isolation practices against natural external factors are generally not seen.

There are 4 composite panels and 1 tile coating application in the neighborhood and there are $0.9 \%$ in 756 buildings.

The brick appearance on the buildings is not the result of the architectural design, but it is the result of leaving the application in the building or leaving the plaster over time. In the neighborhood, $1.43 \%$ brick facade is seen.

In reinforced concrete constructions we usually see glass mosaics as the preferred facade covering material. In the facades where the deformation of the neighborhood is the least, glass mosaic coating is seen after stone facade structures. Glass mosaic facades in 756 buildings were applied with 15.5\%. In the course of time, alternative system preferences that have been formed over time have influenced this region in this region and reinforced concrete applications show 4-5 storied buildings. In the case of wood and masonry structures, usually two or three floor constructions are seen. The current reconstruction plan in the region reopened in 2013 has reduced the floor heights of some applications made in the past. If these formations aimed to reduce the visual disturbances in the region for the next periods, the transformation of a 5-storey building into a 3-storey building and the construction of a desert building were an unfavorable option when property values were calculated. In the buildings inside the neighborhood, incomplete brick facades, chimney plaster-like structures and neglected wooden facades are the front plan.

In this context, façade dressings and floor elevations should be blocked in the streets in order to overcome the silhouette disorders in the Cibali District of cultural richness. Corrupted and unfinished facades from past periods should be supported locally in the context of on-site transformation. 


\section{References}

Ashby, M. ve Johnson, K.(2013). Materials And Design - The Art and Science of Material Selection in Product Design. Elsevier puplisher,. ISBN: 978-9944-757-67-6.

Farrelly,L.(2012). Construction + Materiality ( Yapım + Malzeme ). Çevirmen: Derya Nüket Özer.

Gezer, H.(2005). Dış Cephe Kaplamalarında Polimer Esaslı Malzemenin Uv, Isı ve Suyun Bileşik Etkisi Karşısında Yüzey Dayanıklılığın Araştılması, Doktora Tezi, Mimar Sinan güzel Sanatlar Üniversitesi, İstanbul. ISBN: 978975-04-0596-9.

Hegger, M. ve Auch.Schwelk, V. ve Fuchs, M. ve Rosenkranz, T.(2012). Construction Materials Manual. Puplisher: Birkhauser Boston, Berlin ISBN: 978-975-04-0596-9.

Hegger, M. ve Drexler, H. ve Zeumer, M.(2012).Çevirmen: Volkan Atmaca. Adım Adım Yapi Malzemeleri. Yem Yayın, İstanbul. ISBN: 978-9944-757-67-6.

Literatür Yayınları, İstanbul. ISBN: 978-975-04-0596-9.

Tekin, Ç.(2008). Giydirme Cephe Tasarımındaki Kriterler, Bildiri ISBN: 978-9944-757-67-6.

Toydemir, N. ve Gürdal, E. ve Tanaçan, L. (2011). Yapı Elemanı Tasarımında Malzeme. Literatür Yayınları üçüncü basım, İstanbul. ISBN: 978-975-04-0604-1.

Türkçü, Ç.(2000). Yapım. Birsen Yayınevi, İstanbul. ISBN: 978-9944-757-67-6.

Yeang, K.(2006). Ecodesign- A Manual for Ecological Design. Publisher: Wiley-Academy, London. ISBN:978975-04-0604-1. 